$$
\begin{aligned}
& \text { دراسة العلاقة بين مؤشرات التثوث العضوي في المياه } \\
& \text { رياض محمود صالح العبيدي } \\
& \text { مركز بحوث البيئة والسيطرة على التلوث العيلي } \\
& \text { جامعة الموصل }
\end{aligned}
$$

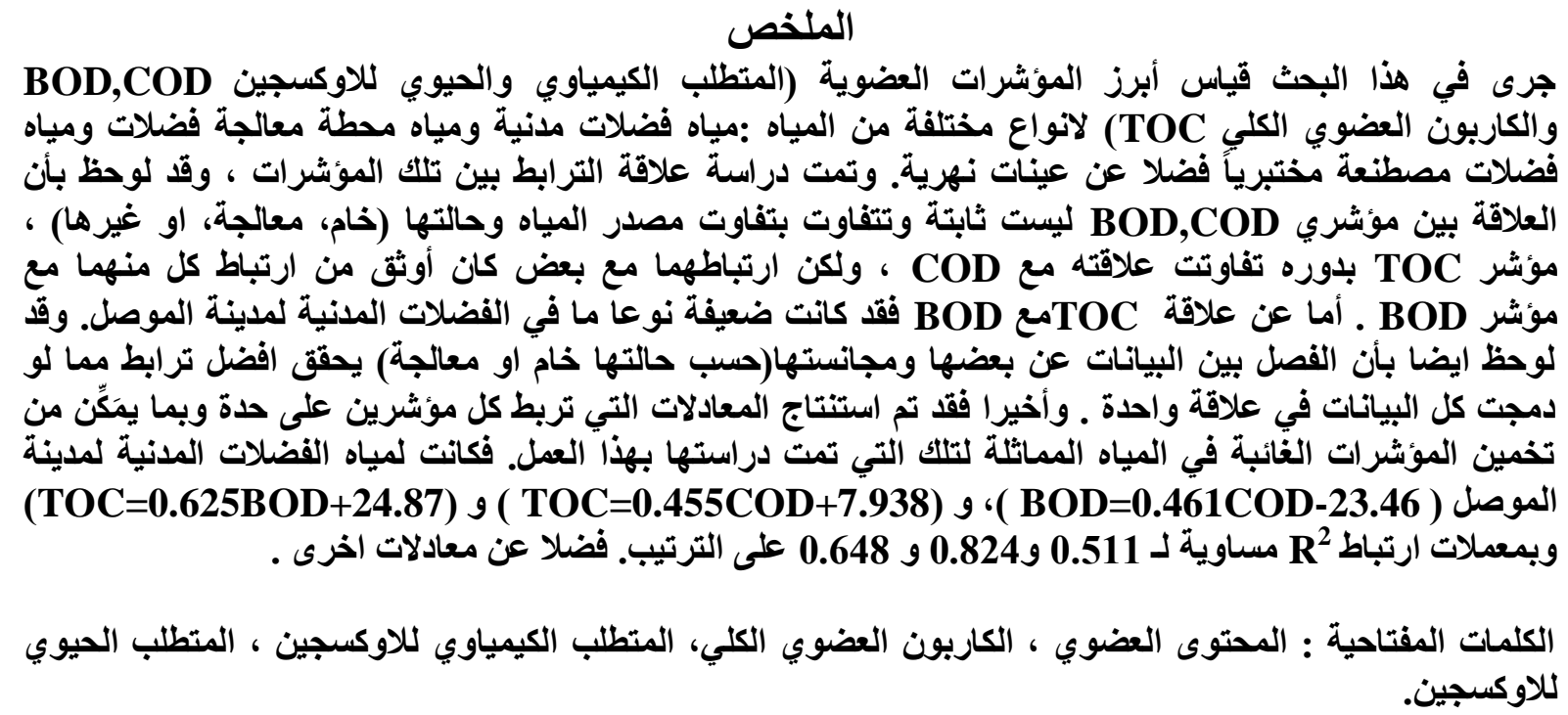

\title{
Study of the Relationship between Organic Content Measures in Water
}

\author{
Riyadh Mahmood Saleh AL-Obaidi
}

Environment and Pollution Control Research Center/Mosul University

\begin{abstract}
:
Organic content measures (COD, BOD, and TOC) has been tested for different types of waters, municipal wastewater, treatment plant influent and effluent, synthetic wastewater and river water samples. The correlation between each two parameters has been studied. The results revealed that the relationship between BOD and COD is not always invariant and its changing depending on the type and the state of the samples (raw, treated or ..etc.). TOC also had changing relationship with COD, however, the TOC,COD relationship was best than the BOD relationship with the other two parameters. The separation between the data and homogenizing them gave best correlation. Finally, equations describing the relation between the three parameters has been edited and they can be used to estimate the absent test in accepted accuracy in similar samples to which have been studied in this work. The equations represent Mosul city wastewater samples were: $(\mathrm{BOD}=0.461 \mathrm{COD}-23.46),(\mathrm{TOC}=0.455 \mathrm{COD}+7.938)$, and (TOC $=0.625 B O D+24.87$ ) with $R^{2}=0.511,0.824$ and 0.648 respectively. More equations are included in this work.
\end{abstract}

Keywords; organic content, TOC, BOD, COD, Correlation , wastewater, characteristics

قبل: 9011 - 2010

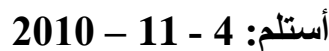


يعد موضوع تحديد خصائص المياه من المواضيع التي تشغل العاملين في مجال هندسة المياه سواء النقية (لتحديد

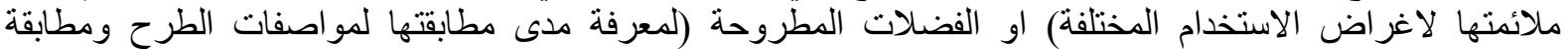

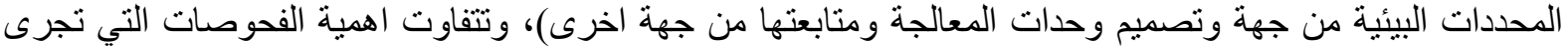

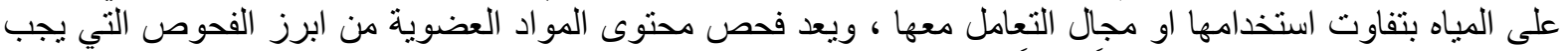

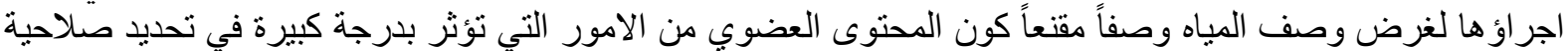
المياه.

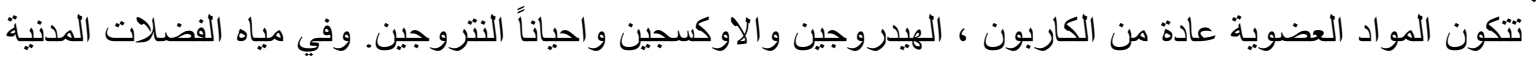

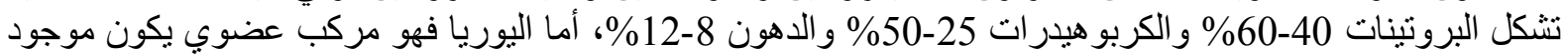

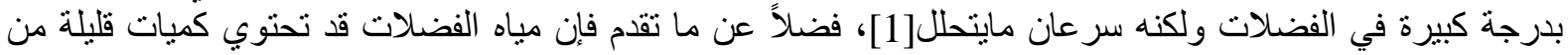

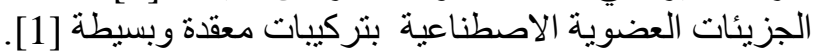

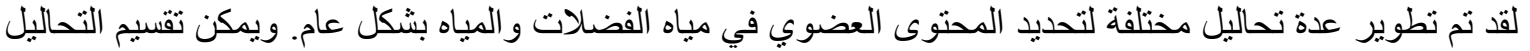

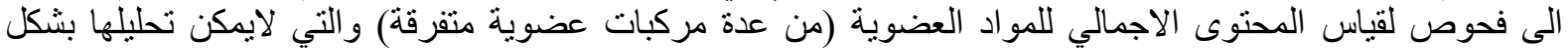

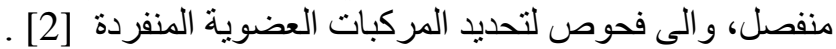

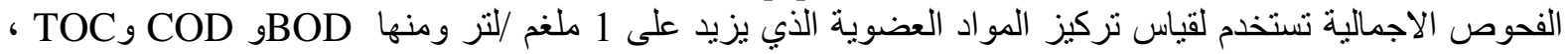

\section{المنطلب الحيوي للاوكسجين Biochemical Oxygen Demand BOD}

في عام 1912 وجدت اللجنة الملكية البريطانية بان فحص الـ BOD5 هو الفحص الامثل لتبيان نوعية مياه الانهر واعتبر

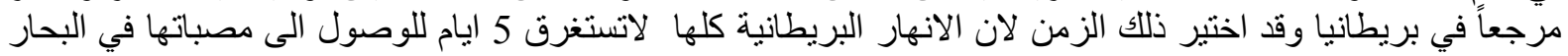

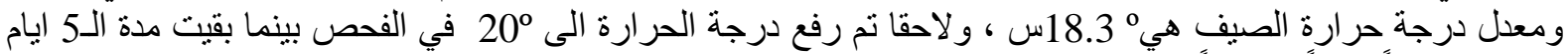

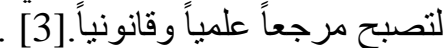

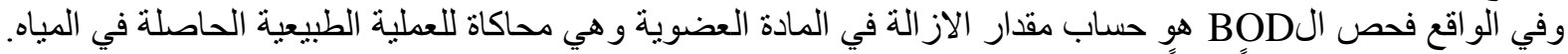

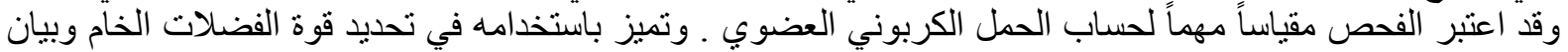

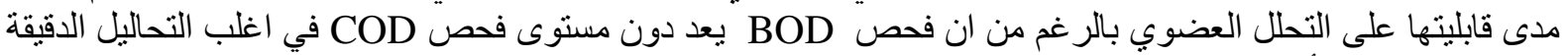

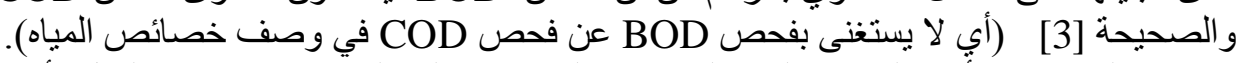

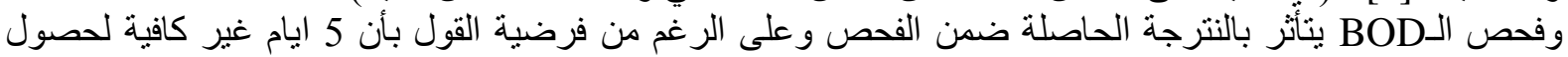

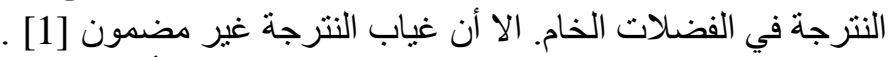

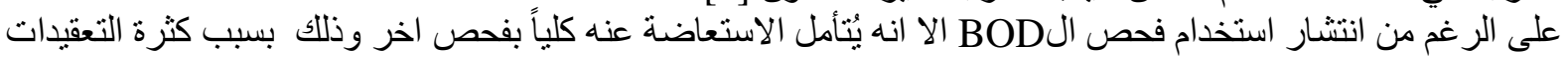

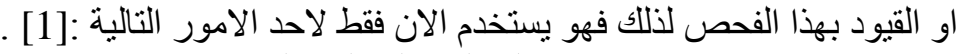

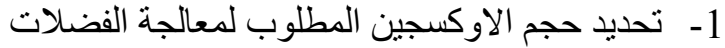

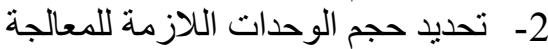

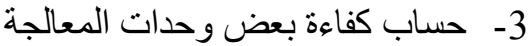
4- تحديد تو افق الفضلات المطروحة مع المعالجة المحددات البيئية.

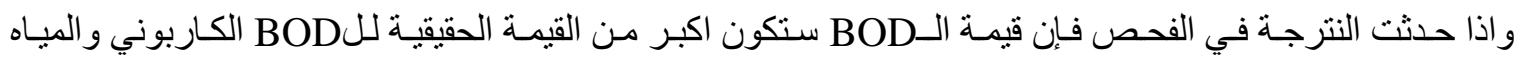

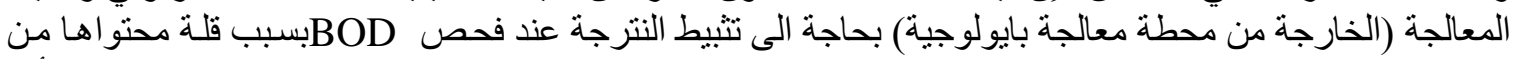

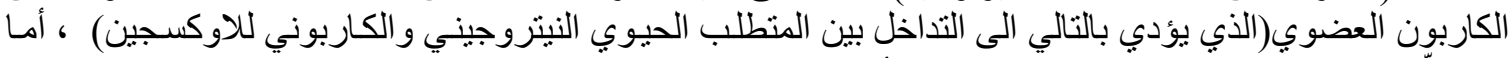

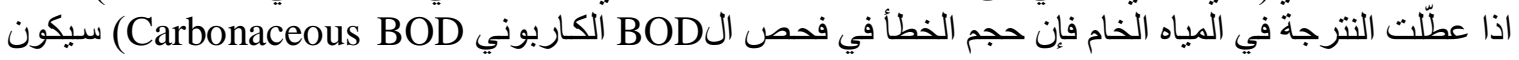

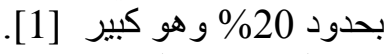
أما القيود التي تسبب التفاوت في فحص الـBOD (وفضلا عن الاخطاء الثخصية واردة الحدوث)

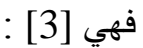

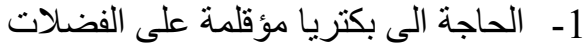

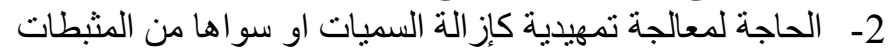
3- اقتصار القياس على المواد العضوية القدان القابلة للتحلل الحيوي.

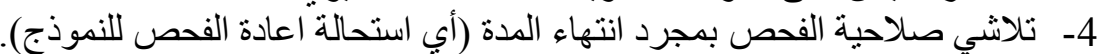

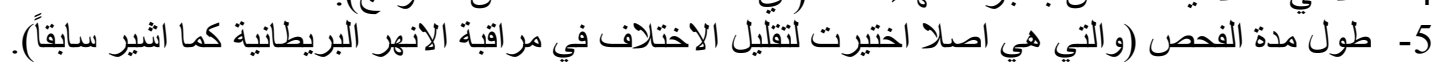




\section{المنطلب الكيمياوي للاوكسجن Chemical Oxygen Demand COD}

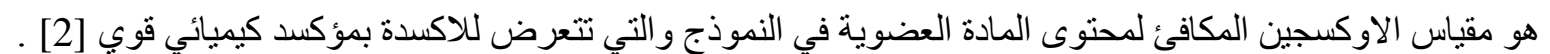

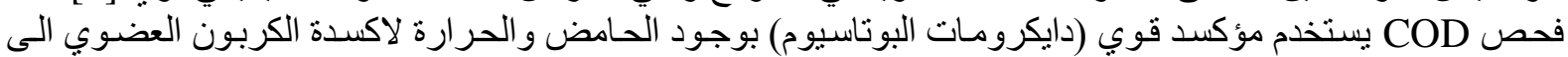

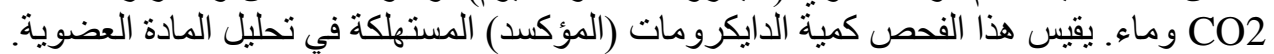

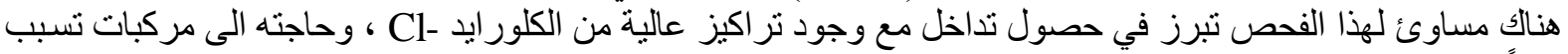

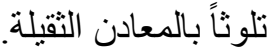
ومن المعروف أن هناك تفاوتاً بين قيم BOD و

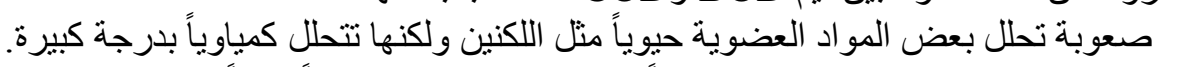

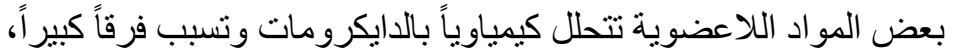

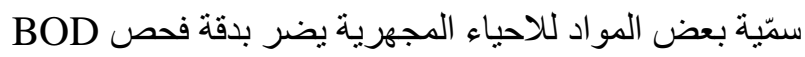

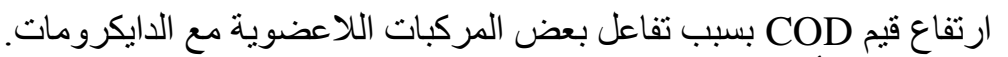

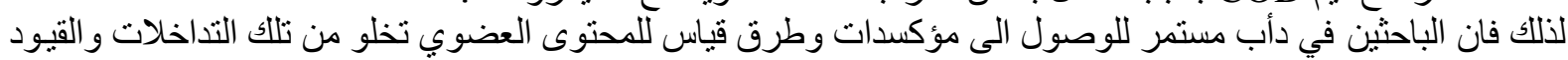

\section{Total Organic Carbon TOC الكاربون العضوي الكلي}

هذا الفحص يتم الياً، وهو لتحديد الكاربون العضوي الكلي في المياه (أي جزيئة الكاربون المرتبطة بمركبات عضوية الكية).

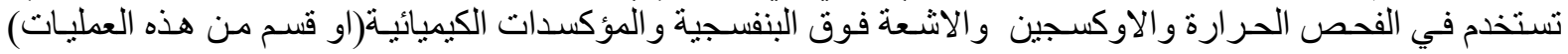

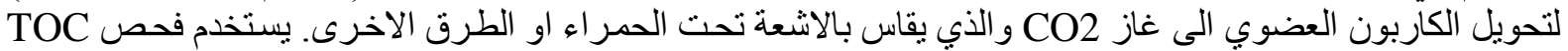

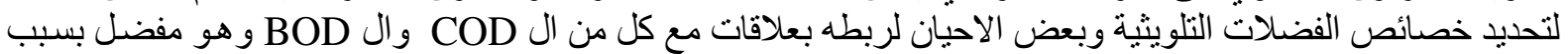

انه قد لا يستغرق أكثر من 20 دقيقة.

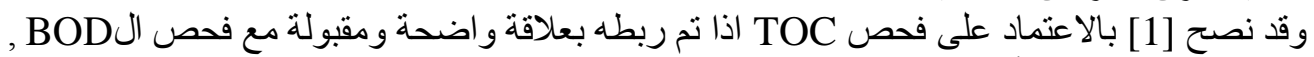
ولهذا الفحص محاسن أهمها : Br 2- 2- الاجة للاحياء المجهرية

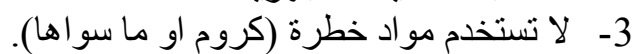

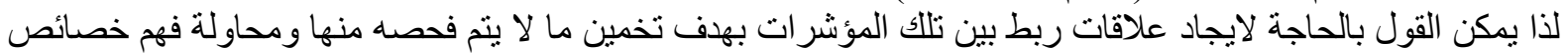

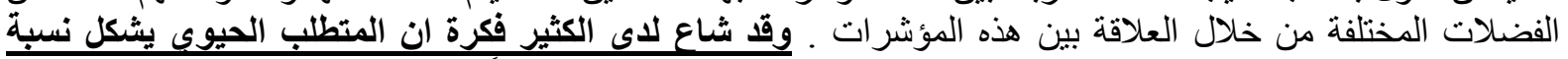

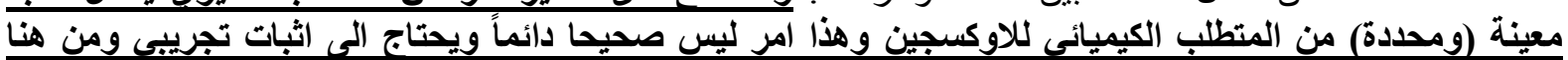

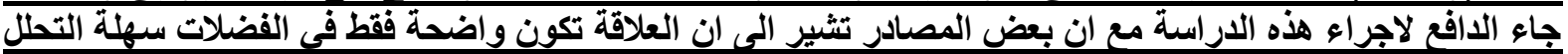

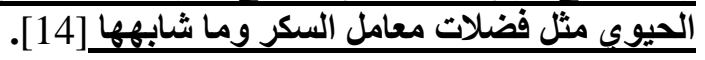

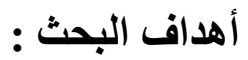

1- ايجاد وصف لعلاقات المؤشر ات الثلاثة (TOC, COD, BOD) مع بعضها .

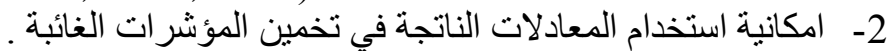

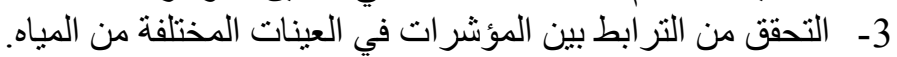

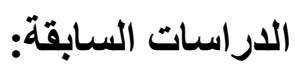

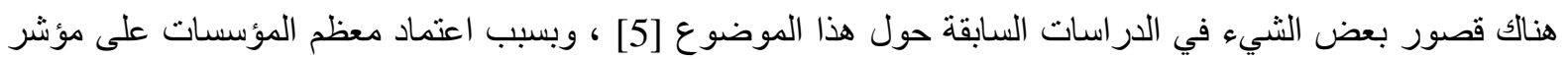

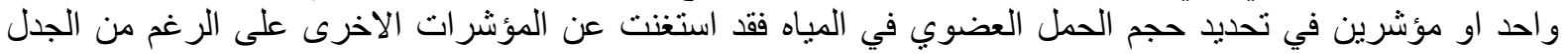

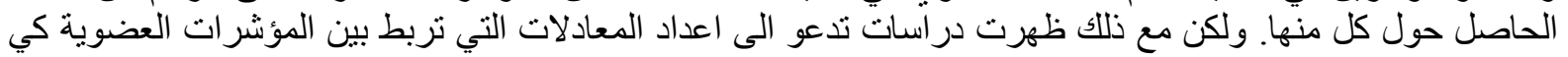

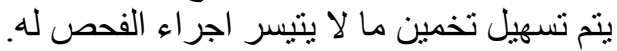

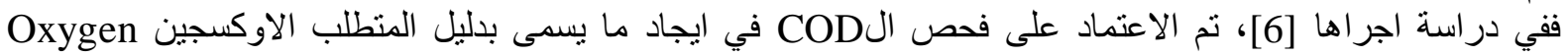

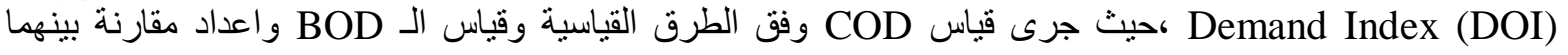


و الاستتناج للاليل الذي يساعد في الاكتفاء بفحص COD بالطريقة اللونية او بالتسحيح ومن ثم تخمين مؤشر BOD بالاعتماد على المعادلة المستنتجة. اما [7] فقد درسوا العلاقة بين المؤشرات العضوية المختلفة (TOC،BOD،COD) وقاً وقد وجدوا اندان العلاقة بين

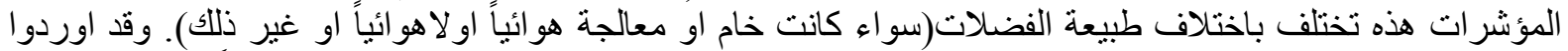

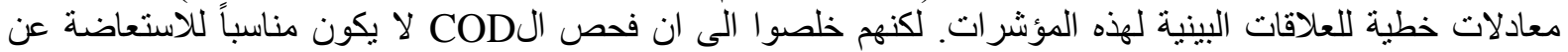

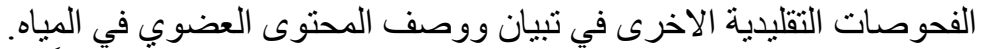

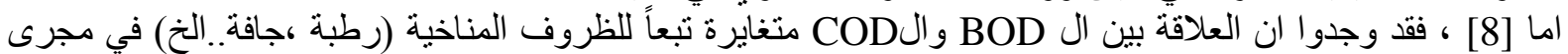

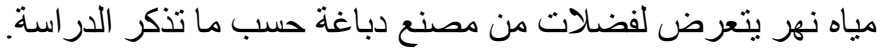

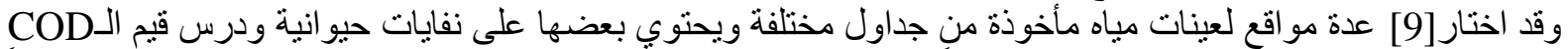

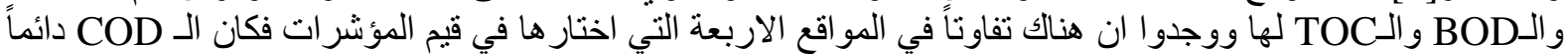

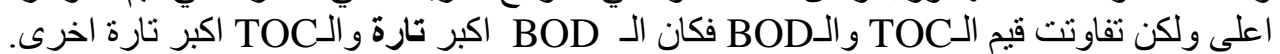

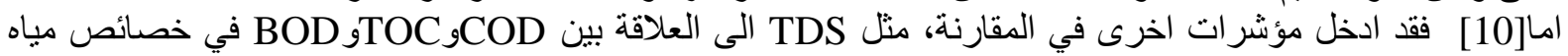

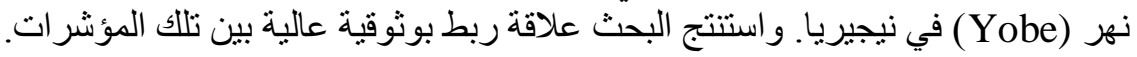

\section{طرائق العمل : - 2 - م}

لاجر اء البحث تم الاعتماد على الطرق القياسية في اجر اء الفحوص المختلفة واهمها : بالمان

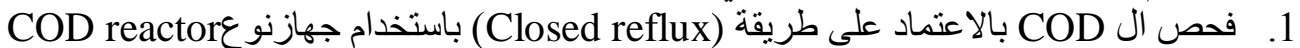

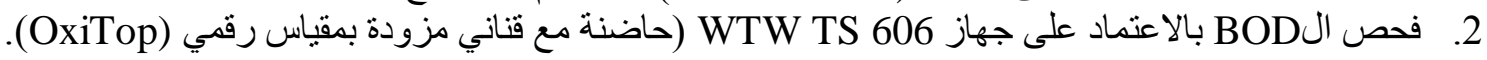

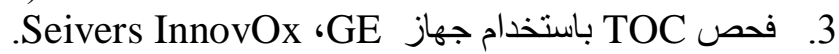

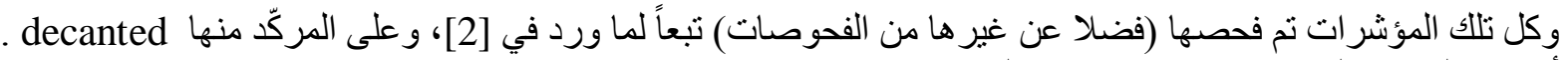

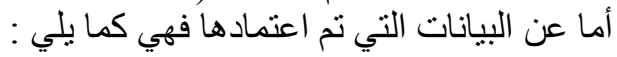

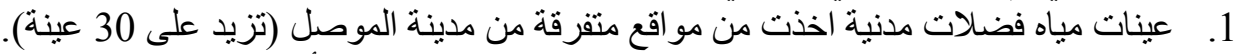

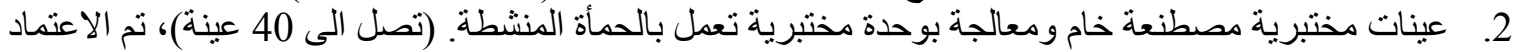

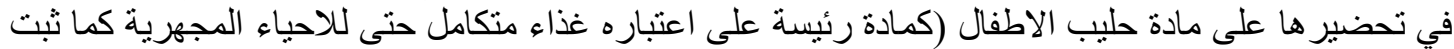

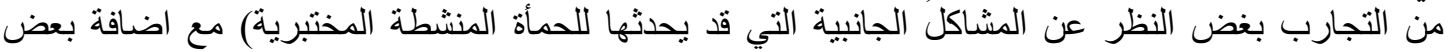

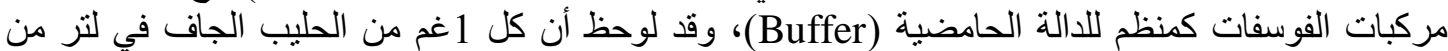

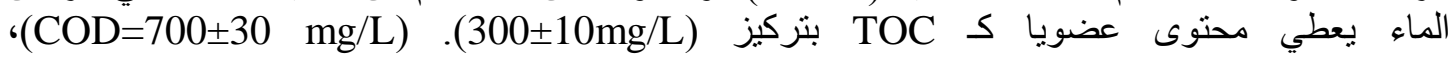

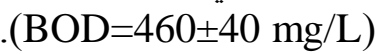

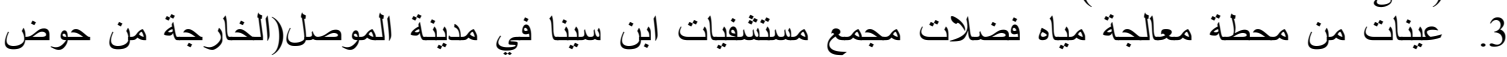

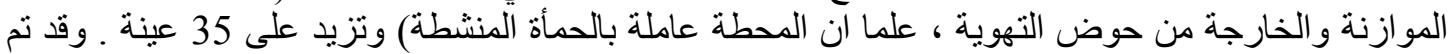

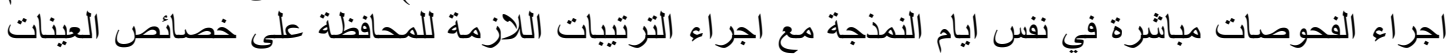

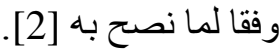

\section{النتائج والمناقشة :}

ان مؤشرات التلوث العضوي المختلفة تعتمد على طرق قياس مختلفة ولكن يمكن القول بانها نشترك في وحدات وندات القياس

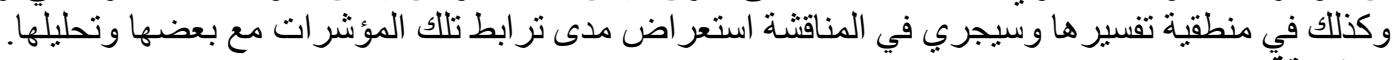

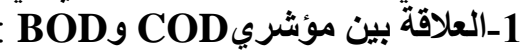

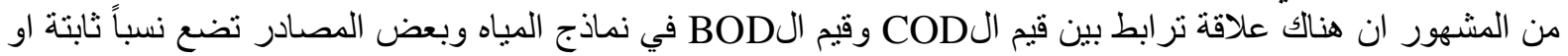

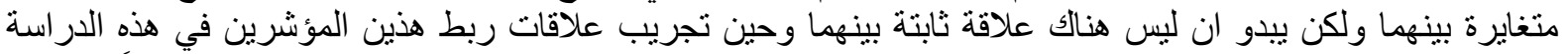

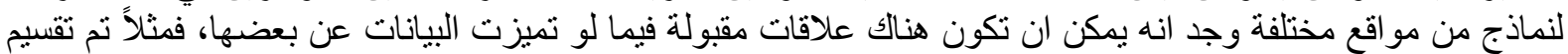

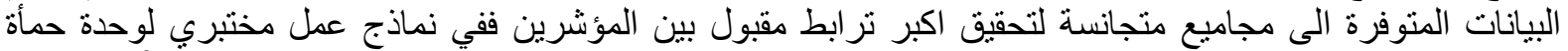

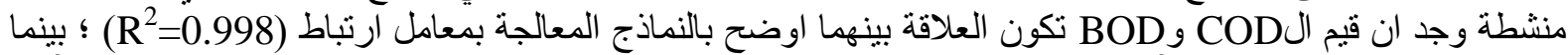

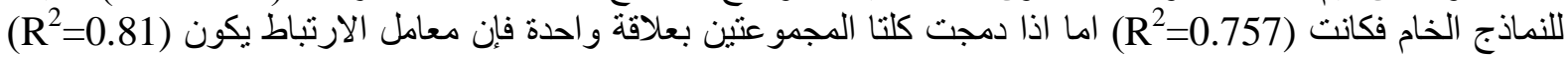

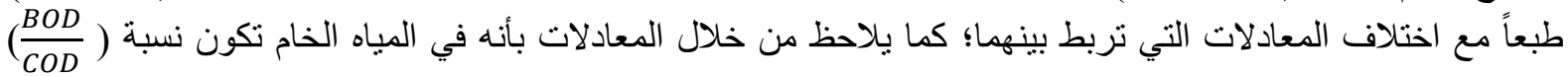
اكبر منها للمياه المعالجة (من خلال ميل المنحني) كون المادة المستخدمة في تحضير المياه الخام (الحليب) سهلة التحلل 
ابتداءً، بينما بعد المعالجة وبسبب ظهور المواد العضوية المقاومة Refractory substances في المياه المعالجة تكون نسبة ( )

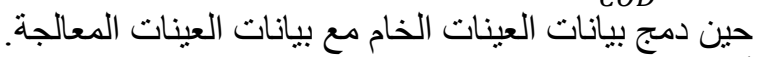

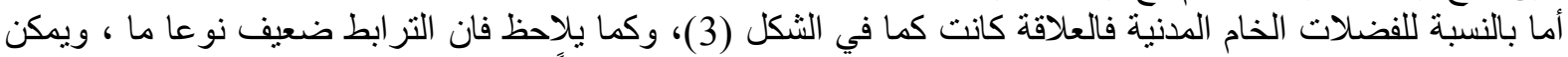

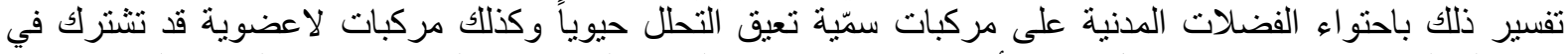

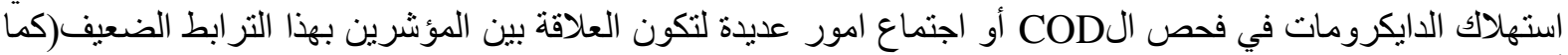

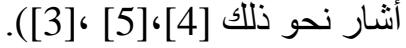

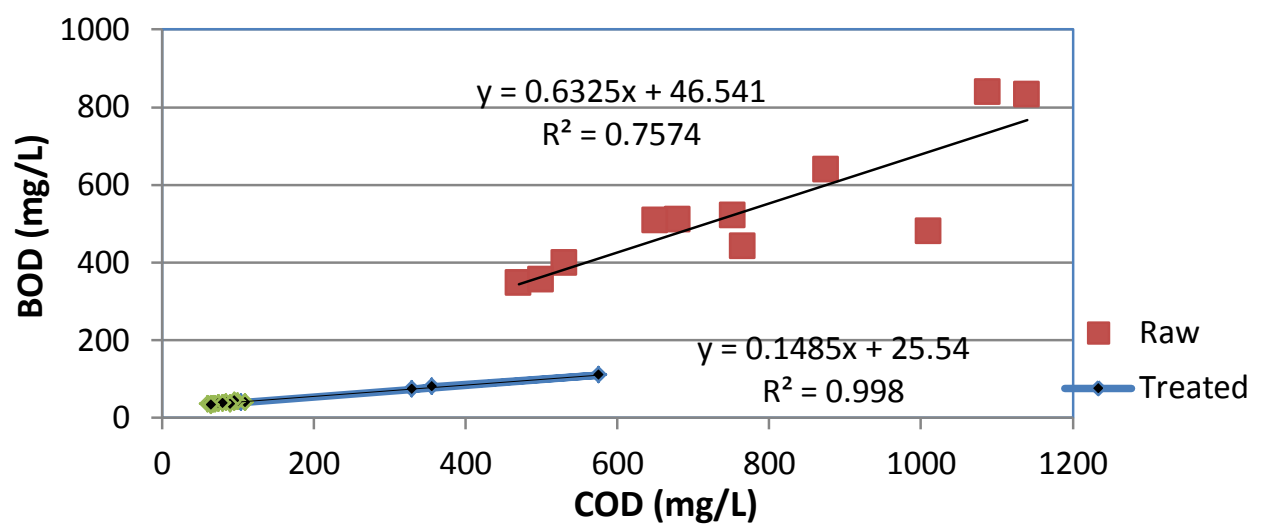

الثكل (1): العلاقة بين مؤشري COD BOD في نماذج مختبرية (اصطناعية) بفصل الخام عن المعالجة.

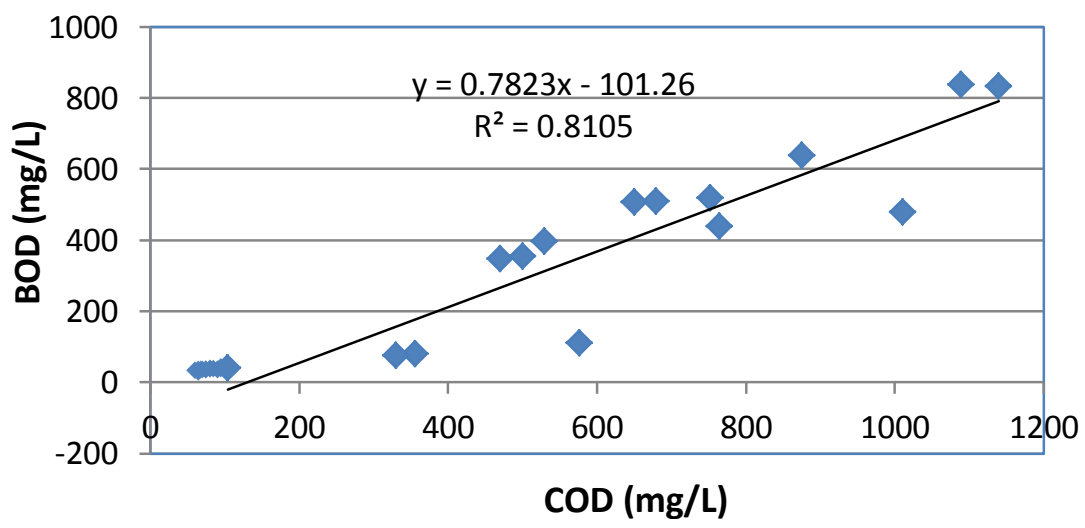

الثكل (2): العلاقة بين مؤشري BODو COD في نماذج مختبرية (اصطناعية) بجمع البيانات الخاصة بالعينات الخام و والمعالجة.

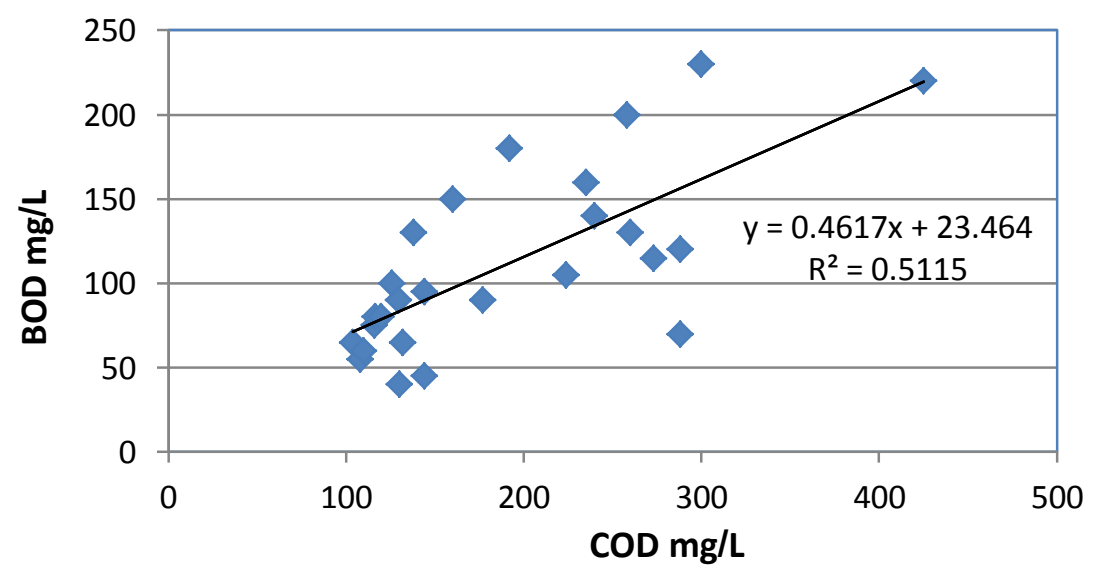

الثكل (3): العلاقة بين مؤشري BOD و COD و COD للفضلات المدنية

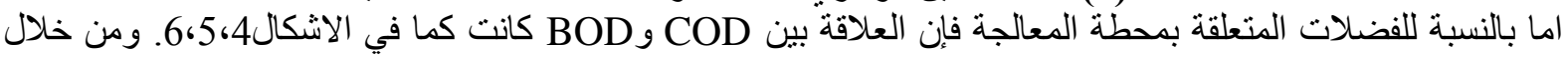

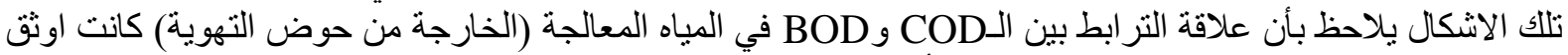

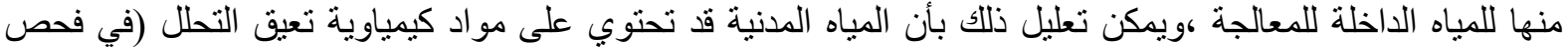


و وبتر اكيز متغايرة مما يربك العلاقة بينCOD وBOD (BOD، بينما بعد معالجتها فإن الفضلات تتجانس وتصبح قيم BOD اكثر معنوية نسبة لقيم BOD

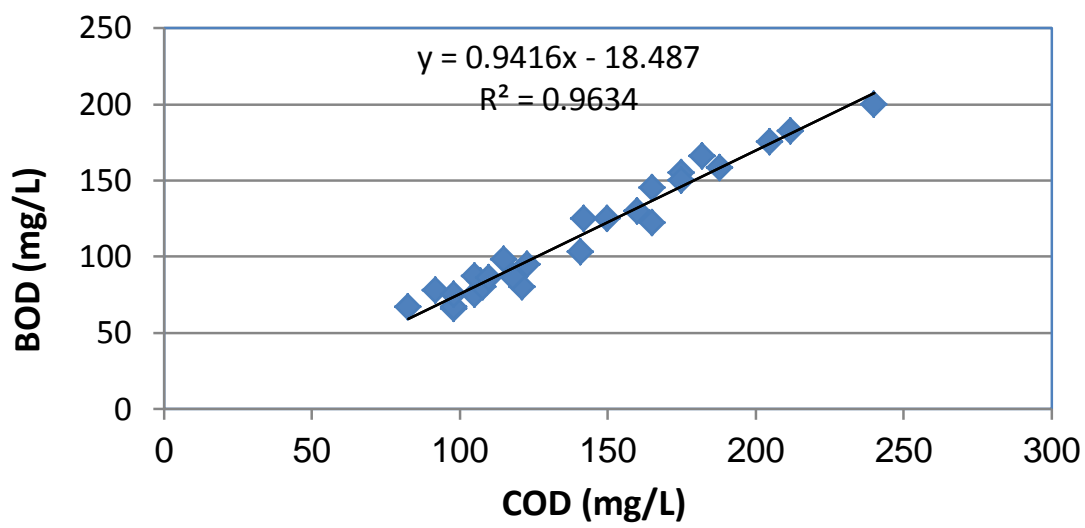

الثكل (4): العلاقة بين مؤشري BOD وBOD في نماذج لمياه خارجة من محطة معالجة فضلات مستشفى .

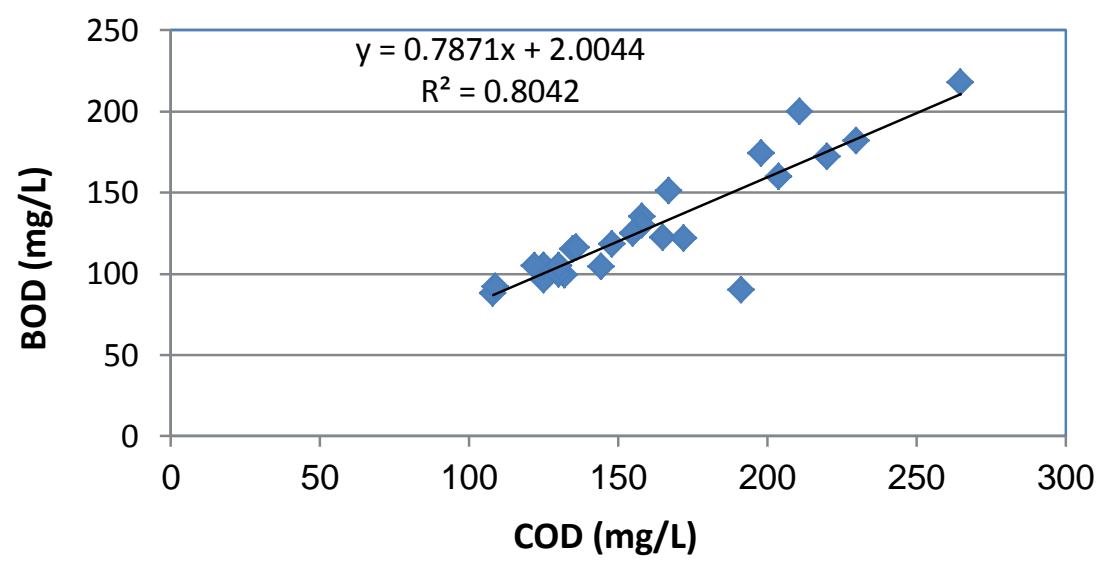

الثكل (5): العلاقة بين مؤشري BODو BOD في نماذج لمياه داخلة لمحطة معالجة فضلات مستشفى .

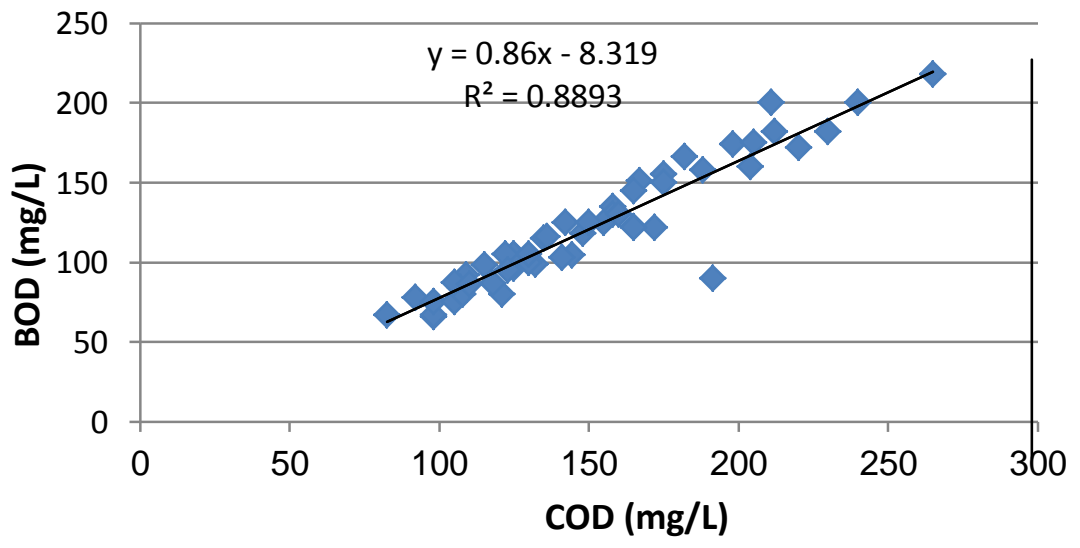

الثكل (6): العلاقة بين مؤشري BODو BOD في نماذج لمياه داخلة ومعالجة في محطة معالجة فضلات مستشفى .

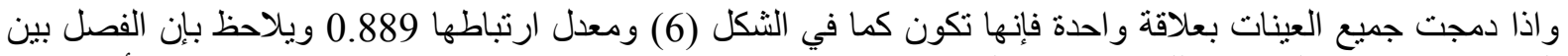

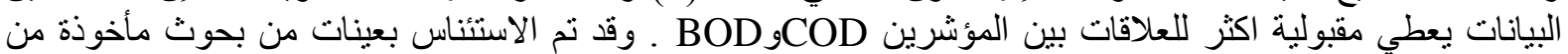

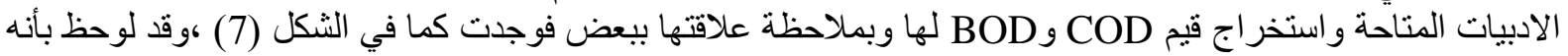

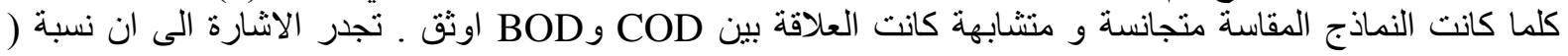

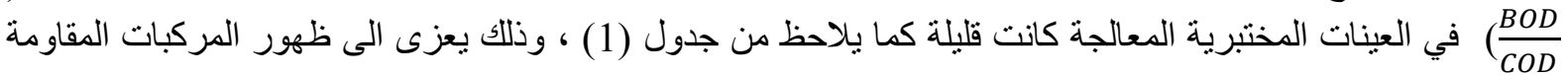


Refractory substances للتحلل الحيوي الحاصل بفحص BOD ، و هذا منو افق مع ما وجده [11]. ويمكن اعتبار

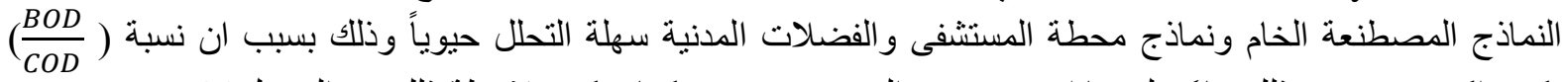
تكون اكبر من 0.5 وذلك بناءً على ما استنتجه نفس المصدر [11] ، وكما يمكن ملاحظة ذلك من الجدول(1).

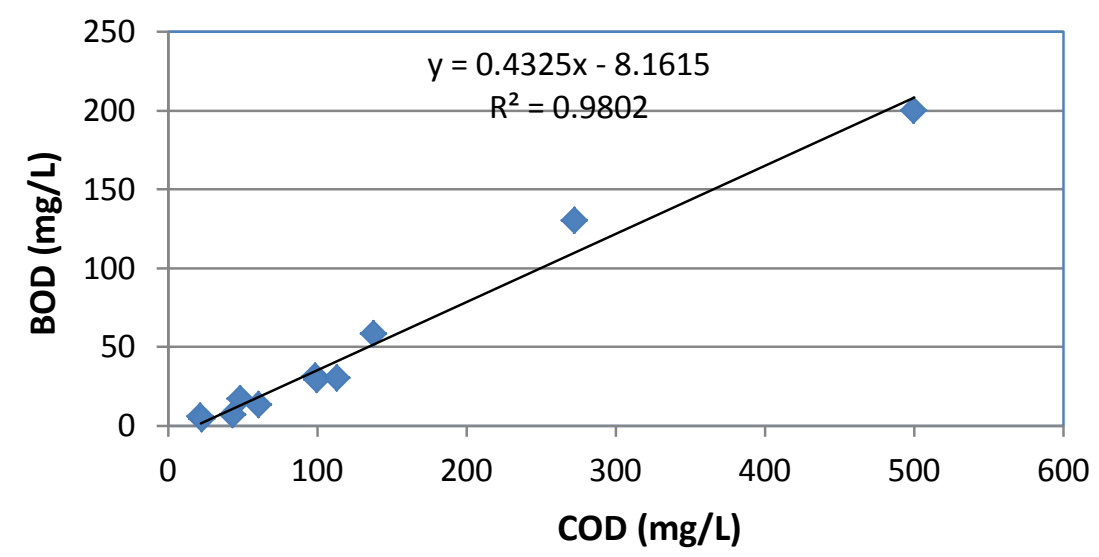

الثكل (7): العلاقة بين مؤشري BODو COD في نماذج لمياه مختلفة ماخوذة من ادبيات عدة ([7].[8].[9] .[10]. .) ([12].[11]

2- العلاقة بين مؤشري الـTOC و COD

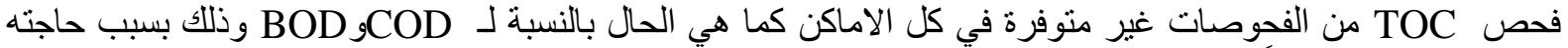

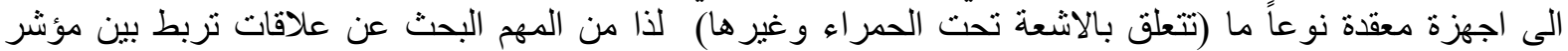

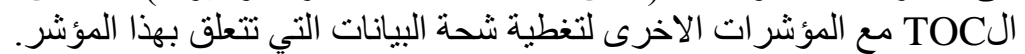
ويختلف فحص TOC عن الفحصين الاخرين في كونه يقيس ذرات الكئ الكاربون في المادة العضوية بينما الفحصين الاخرين

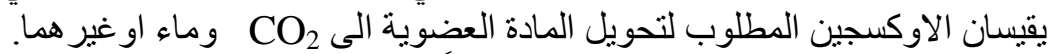

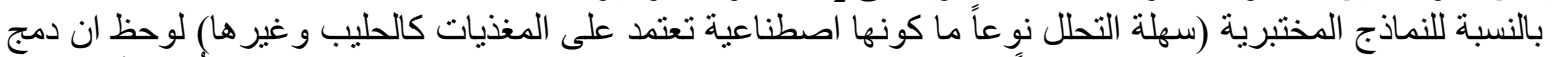

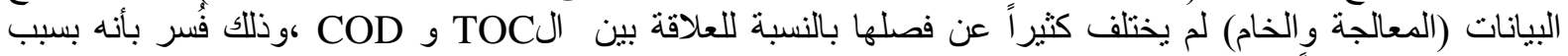
تقارب العلاقة اصلاً بين ذرات الكات الكاربون والمواد العضوية سهلة التحلل(اي في المركبات سهلة التهلة التحلل يكون الكاربون

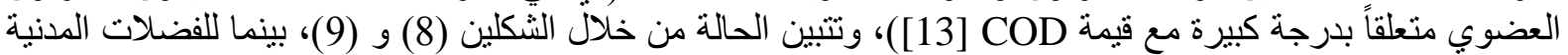
(الثكل 10) فقد تبين ان النسبة بين TOC/COD هي بحدود 0.49 (باختيار تقاطع الخط مع النقطة 0,0)مع احتمالية

تغاير ها بسبب تغاير تركيبة الفضلات بشكل مستمر ـ

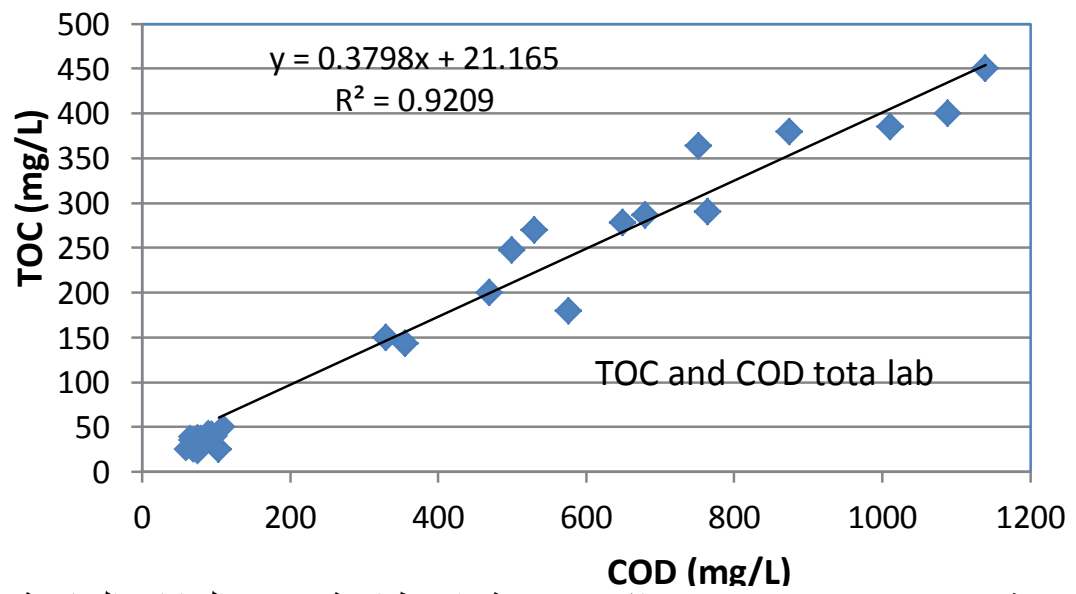

الشكل (8): العلاقة بين مؤشري COD وTOC في نماذج مختبرية (اصطناعية) بجمع البيانات الخاصة بالخام 


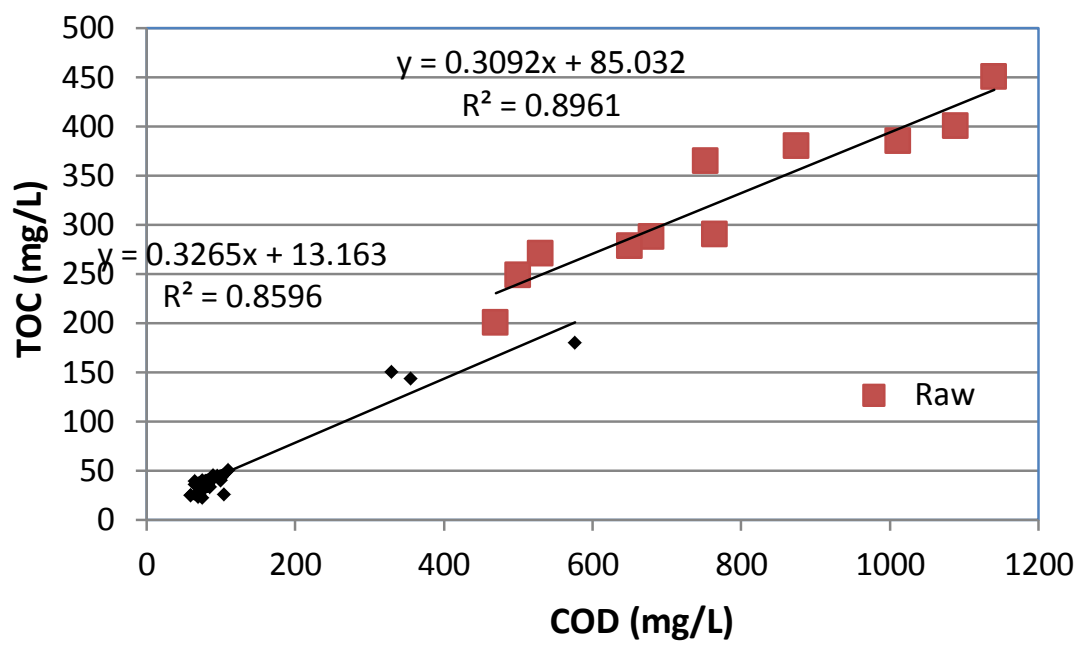

الثكل (9): العلاقة بين مؤشري COD وTOC في نماذج مختبرية (اصطناعية) بفصل الخام عن المعالجة.

اما للبيانات المأخوذة من الأدبيات فكانت العلاقة كما مبينة في الثكل (11).

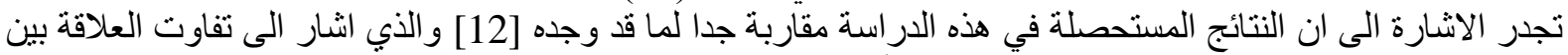

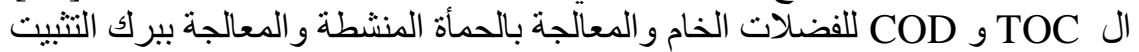

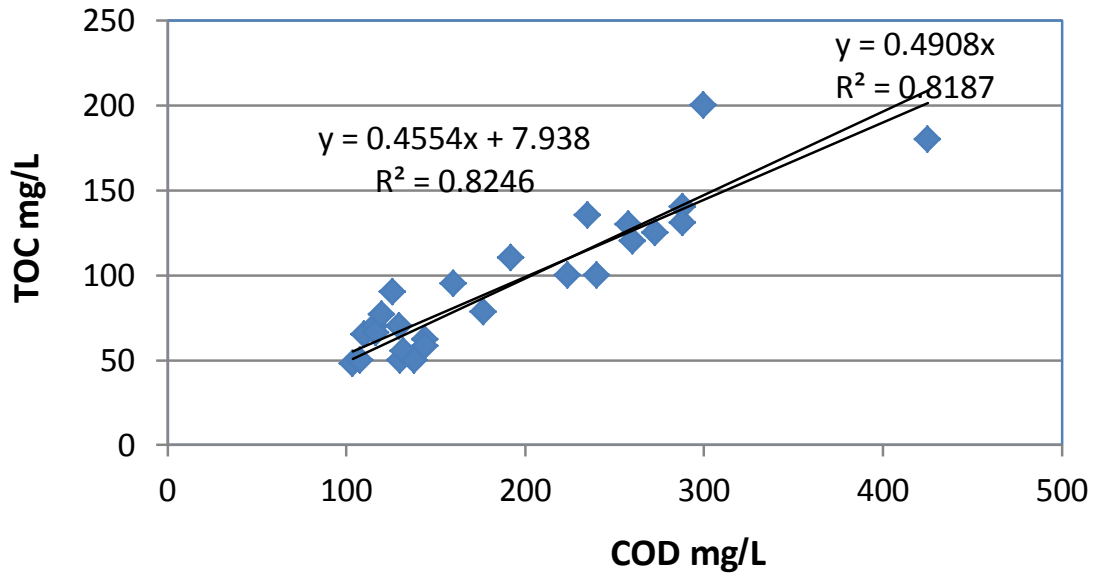

الثكل (10): العلاقة بين مؤشري COD وTOC لفضلات مدنية .

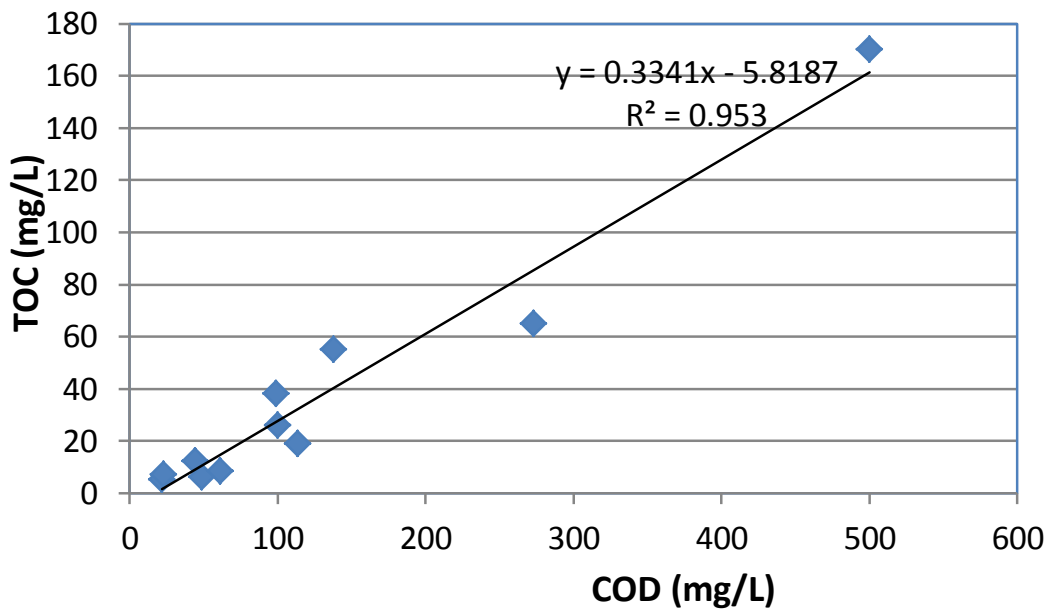

الثكل (11): العلاقة بين مؤشري COD وTOD في نماذج لمياه مختلفة ماخوذة من ادبيات عدة. ([7].[8].[9] .[10]. 
3-العلاقة بين مؤشري TOC و

يمكن ملاحظة علاقة هذين المؤشرين مع بعضهما للبيانات المختبرية من خلال الثكل(12) وكما مبين فإن فصل البيانات

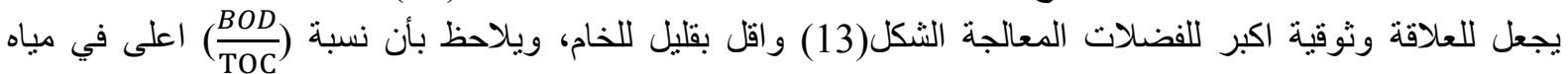

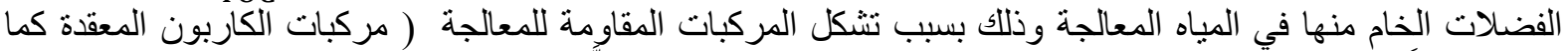

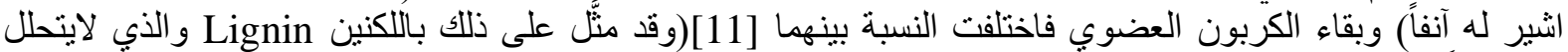

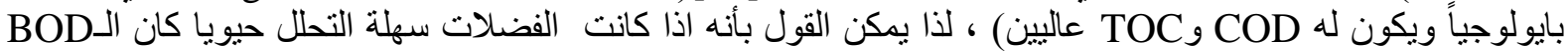

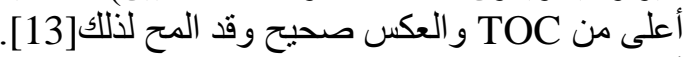

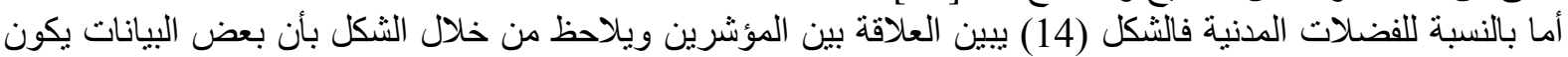

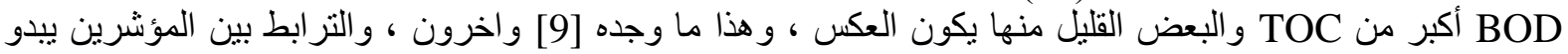

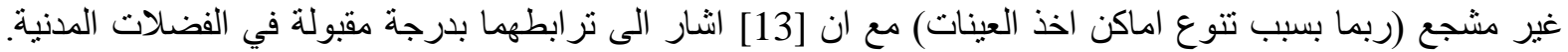

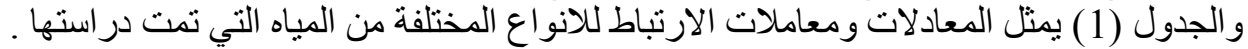

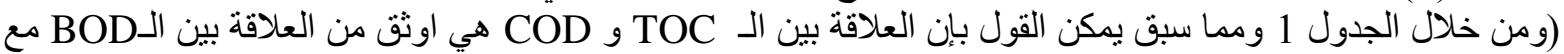

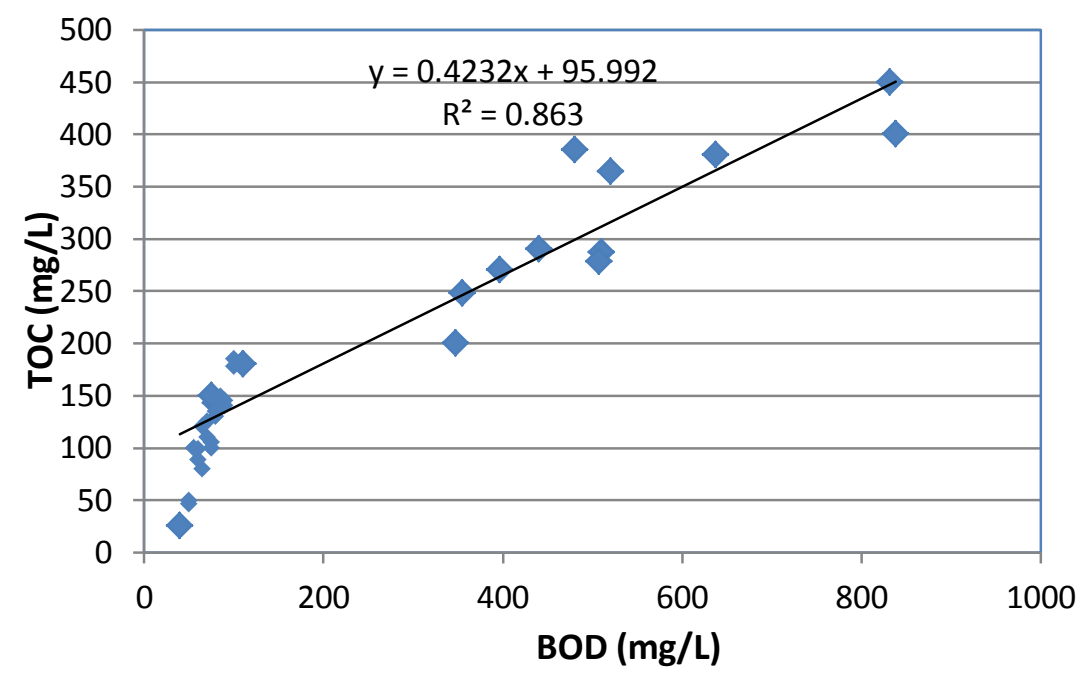

كل منهما).

الثكل (12): العلاقة بين مؤشري BOD وTOC في نماذج مختبرية (اصطناعية) بجمع البيانات الخاصة بالخام و المعالجة.

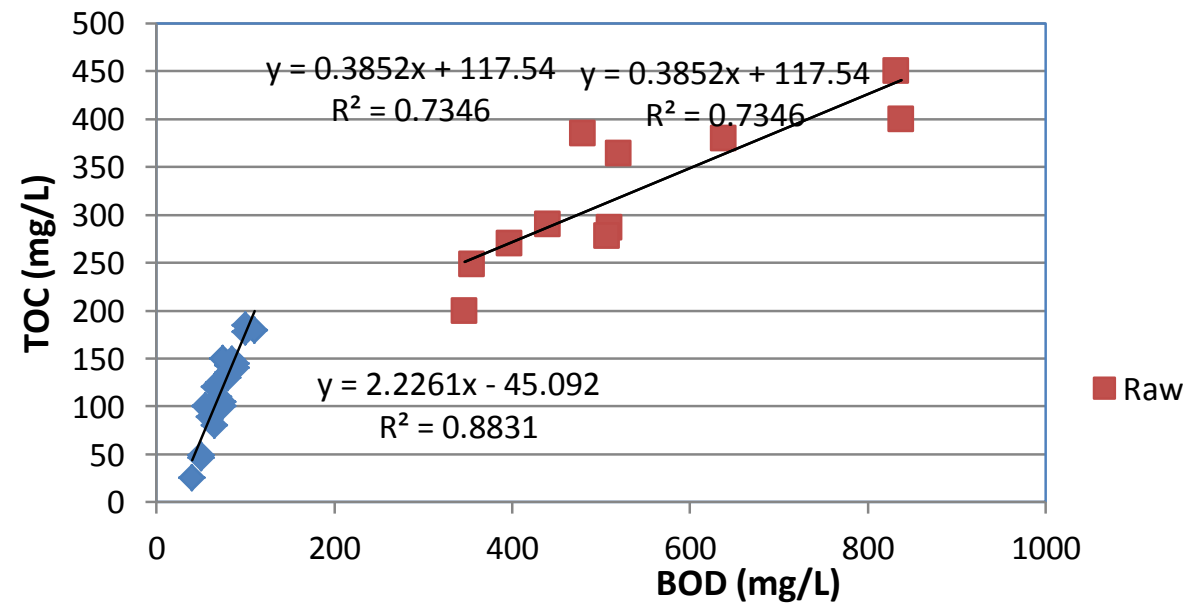

الثكل (13): العلاقة بين مؤشري BOD وTOC في نماذج مختبرية (اصطناعية) بفصل الخام عن المعالجة 

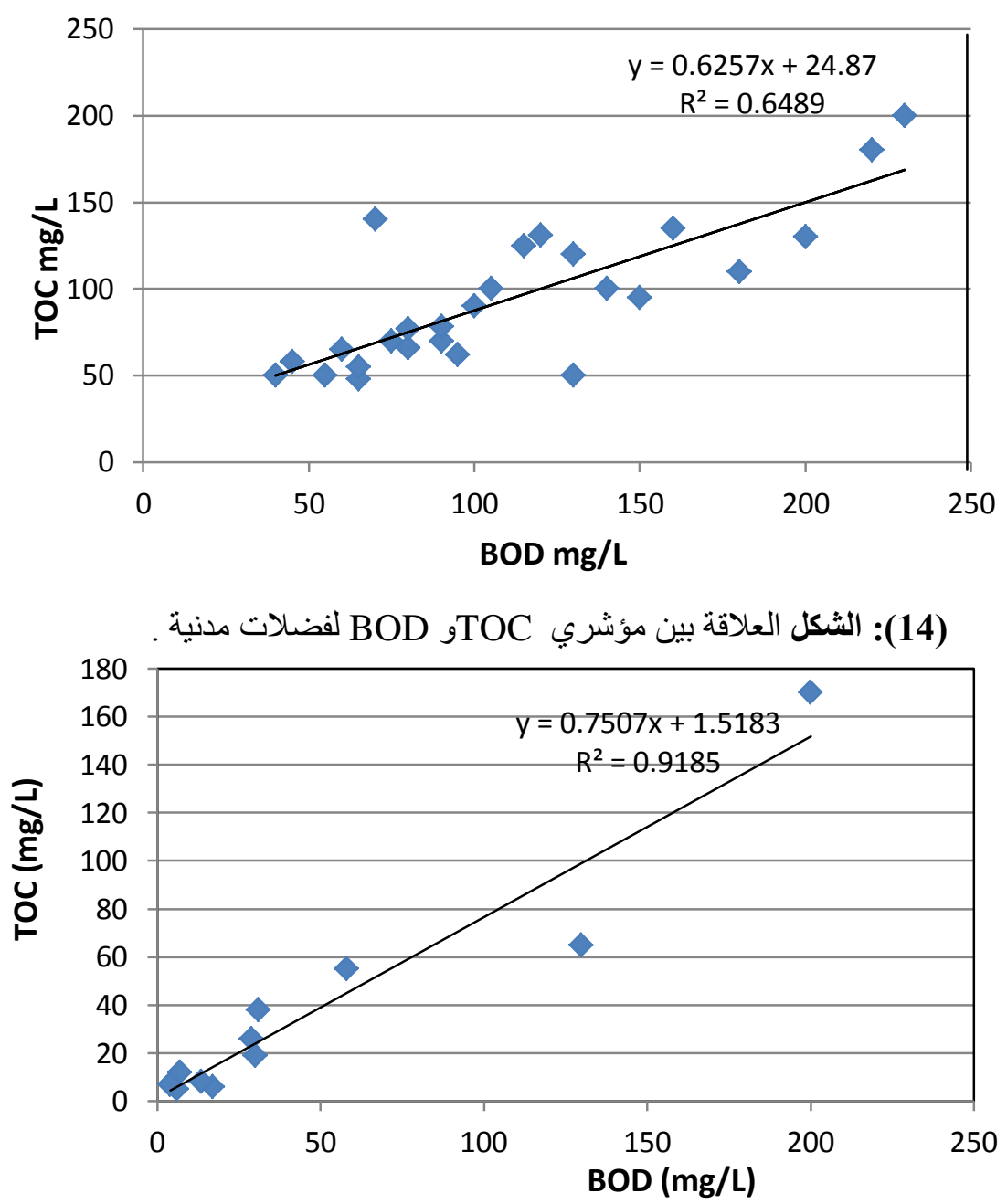

الثكل (15): العلاقة بين مؤشري BOD وTOC في نماذج لمياه مختلفة ماخوذة من ادبيات عدة ([7].[8].[9] .[10].]. ..([12].[11]

الجدول (1) : المعادلات التي تمثل العلاقة بين المؤشرات العضوية المختلفة

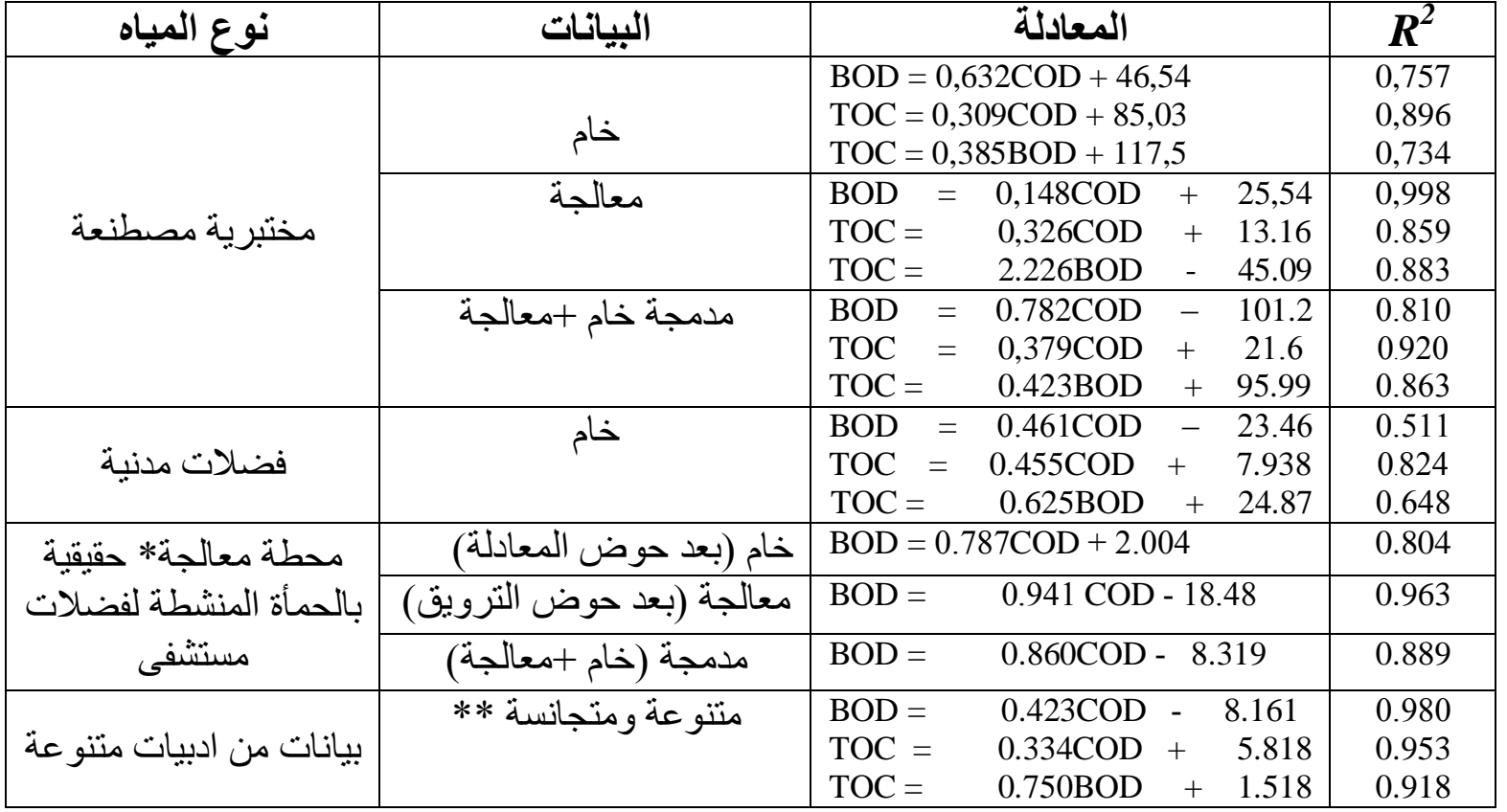


*لم يتم التمكن من فحص محتوى الكاربون العضوية لأسباب فنية. و هذه الصحطة هي محطة الصرف الصحي الخاصة

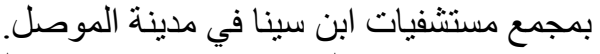

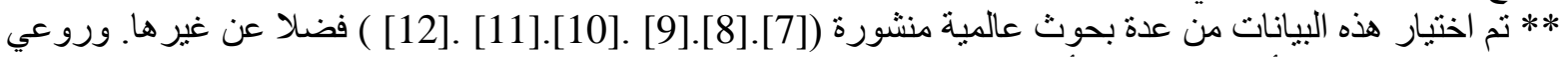

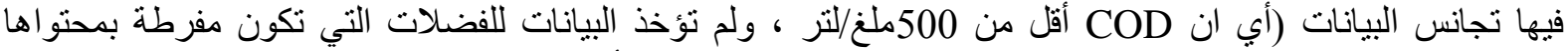
العضوي او التي يتوقع حاجتها لنسب عالية جدا من التخفيف، لتلافي الخطأ المتر اكم في المعادلات التيات المستنتجة).

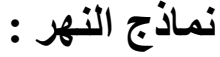

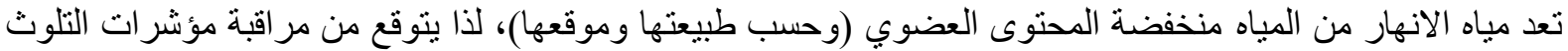

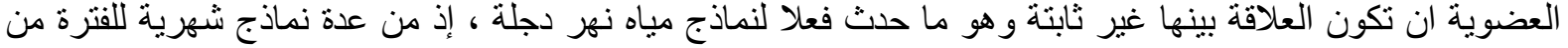

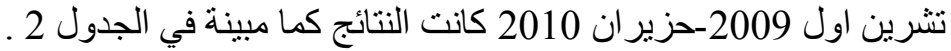

الجدول(2): مؤشرات التلوث العضوي في مواقع من نهر دجلة 1 في مدينة الموصل

\begin{tabular}{|c|c|c|c|}
\hline الموقع من النهر22 & $\mathrm{COD}(\mathrm{mg} / \mathrm{L})$ & $\mathrm{BOD}(\mathrm{mg} / \mathrm{L})$ & TOC $(\mathrm{mg} / \mathrm{L})$ \\
\hline مشيرفة & $10.5( \pm 4.5)^{3}$ & $6.0( \pm 3.2)$ & $3.4( \pm 2.1)$ \\
\hline الدندان & $7.5( \pm 3.5)$ & $5.2( \pm 4.9)$ & $0.8( \pm 0.7)$ \\
\hline الثرطة النهرية & $5.0( \pm 2.6)$ & $4.3( \pm 1.5)$ & $0.2( \pm 0.3)$ \\
\hline الحي العربي & $8.5( \pm 5.1)$ & $3.5( \pm 2.5)$ & $2.1( \pm 1.8)$ \\
\hline البوسيف & $16.5( \pm 9.5)$ & $11.2( \pm 5.5)$ & $4.4( \pm 2.1)$ \\
\hline
\end{tabular}

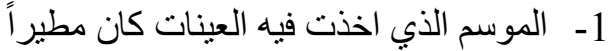

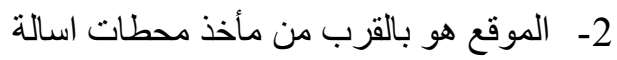

3- 2 - الانحر اف القياسي

و اذا ما أخذنا اجمالي البيانات وربطناها بعلاقات تر ابط فانها تكون كما يلي :

$B O D=0.64 C O D-0.104 \quad\left(R^{2}=0.836\right)$

TOC $=0.379 C O D-1.459 \quad\left(R^{2}=0.882\right)$

TOC $=0.440 B O D-0.480 \quad\left(R^{2}=0.583\right)$

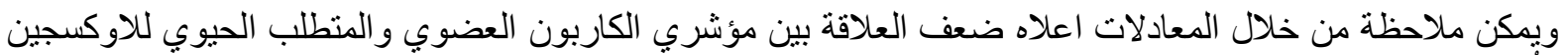

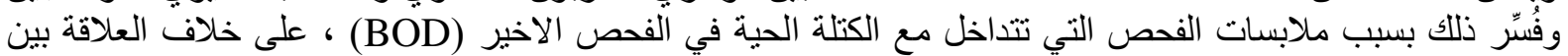

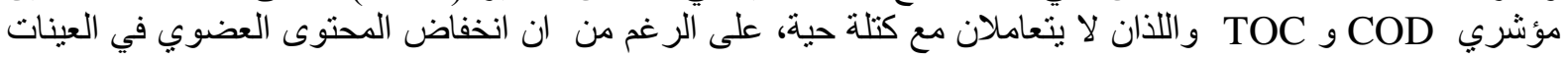

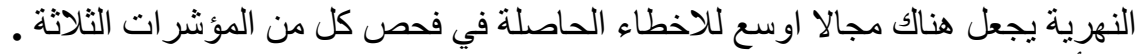
وقد أثنار [1] الى ان النسبة النظرية بين TOC/BOD هي 0.37 و هي مقاربة لما وجد اعلاه .

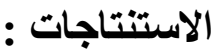

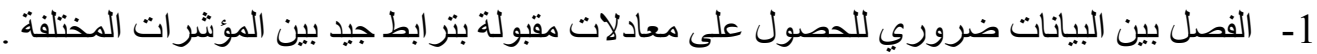

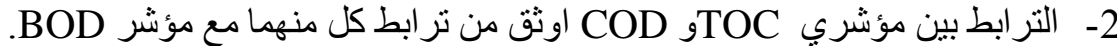

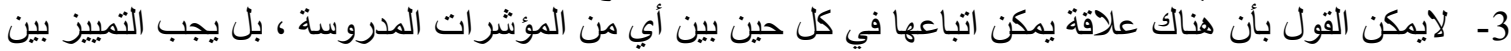

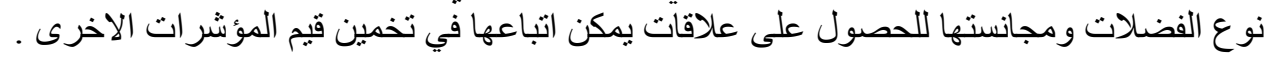


المصادر "

1. Metcalf and Eddy (2004) "Wastewater Engineering, Treatment and Reuse" $4^{\text {th }}$ ed. International Edition, McGraw Hill, Singapore.

2. American Public Health Association, AWWA and WEF (2005) Standard Methods for the Examination of Water and Wastewater, $21^{\text {st }}$ Edition. American Public Health Association, Washington, DC.

3. Tchobanoglous, George \& Schoeder, Edward D.,(1985) Water Quality Characteristics : Modeling \& Modification, Reading, MA: Addison-Wesley Publishing Co/May,.

4. Pisarevsky, A, M., Polozova, I.P., Hockridge, P.M. (2005) "Chemical Oxygen Demand" Russian journal of Applied Chemistry, vol. 78, No. 1, pp 101-107.

5. Rene, E R.; Saidutta, M. B. (2008), "Prediction of Water Quality Indices By Regression Analysis and Artificial Neural Networks" . International Journal of Environmental Research. 2(2): pp 183-188.

6. Shiver, L.E; Young, J. C. (1972). "Oxygen Demand index as a rapid estimate of biochemical oxygen demand" Journal of WPCF, Tchnical report.

7. Fadini ,P.S.; Jardim, W.F. and Guimarães, J.R. (2004) "Evaluation of Organic Load Measurement Techniques in a Sewage and Waste Stabilisation Pond" . J. Braz. Chem. Soc., Vol. 15, No. 1, 131-135.

8. Akan,J.C.: Abdulrahman,F.I; Ayodele , J. T. And Gugbuaja, V.O.(2009) " Impact Of Tannery And Textile Effluent On The Chemical Characteristics Of Challawa River, Kano State, Nigeria" EJEAFChe, 8 (10), 2009. pp1008-1032.

9. Hill, D.D.; Owens , W. E. and Tchounwou, P.B. (2005). " Comparative Assessment of the Physico-Chemical and Bacteriological Qualities of Selected Streams in Louisiana" . International Journal of Environmental Research and Public Health 2(1), 94-100.

10. Waziri, M. And Ogugbuaja, V. O. (2010) " Interrelationships between physicochemical water pollution indicators: A case study of River Yobe-Nigeria", American Journal Of Scientific And Industrial Research, 1(1), 76-80.

11. Kindsigo, M. and Kallas,J. (2006), " Degradation of lignins by wet oxidation: model water solutions" Proc. Estonian Acad. Sci. Chem., 2006, 55, 3, 132-144.

12. Friedler, E. ; Juanico,M. and Shelef, G. (2003)," Simulation model of wastewater stabilization reservoirs" Ecological Engineering (20), pp 121-145.

13. Ramalho, R.S. (1977) " introduction to wastewater treatment processes" ACADEMIC PRESS. London . UK .

14. Eckenfelder J. W. (1998) " Industrial Water Pollution Control" . McGraw-Hill, New York.

تم اجراء البحث في مركز بحوث البيئة السيطرة على التلوث = جامعة ألموصل 